\title{
INTRODUCTION
}

\section{A GRAVE FOR TEETH, A GRAVE FOR BOOKS}

When Yao Wenyu lost a tooth sometime around dingmao (1867), her family kept it. At that moment, this wife, mother, and grandmother in a prominent scholar's family was just beginning years of relative prosperity and stability after frequent moves and separations from her husband in the first decades of their marriage (see figure I.1). Some of their wanderings had been spurred by the vicissitudes of his career, some by the Taiping civil war that wracked China in the 1850s and early 1860s. In renwu (1882), three years after her death, her widower Yu Yue (1821-1907) buried her tooth together with one he had lost the previous year, inscribing the tiny grave with a poem. To his astonishment, a Japanese admirer heard the story and sent him a poem commenting on the tooth grave. When Yu later summed up his life in a series of quatrains, one poem opens with a description of the tooth grave, and closes with amazement that news of it should travel so far. ${ }^{1}$ Completing the circle, the autobiographical quatrain series containing this exchange was itself reprinted in Japan a year after it was published in China. ${ }^{2}$ The actual tooth grave near where Yu Yue lectured on the Confucian classics by West Lake in Hangzhou has long since vanished, but the poem survives, circulating with Yu's collected works. ${ }^{3}$

Because of Yu Yue's prolific writing and its wide distribution, a whimsical yet mournful act, creating the tooth grave as a miniature of the shared grave where the widower will one day lie beside his wife, has an international audience. In the fifteen years between Yao Wenyu's loss of the tooth and Yu's monument, he rose from a dismissed official, albeit with influential friends, to the director of one of the country's most prominent Confucian academies and one 


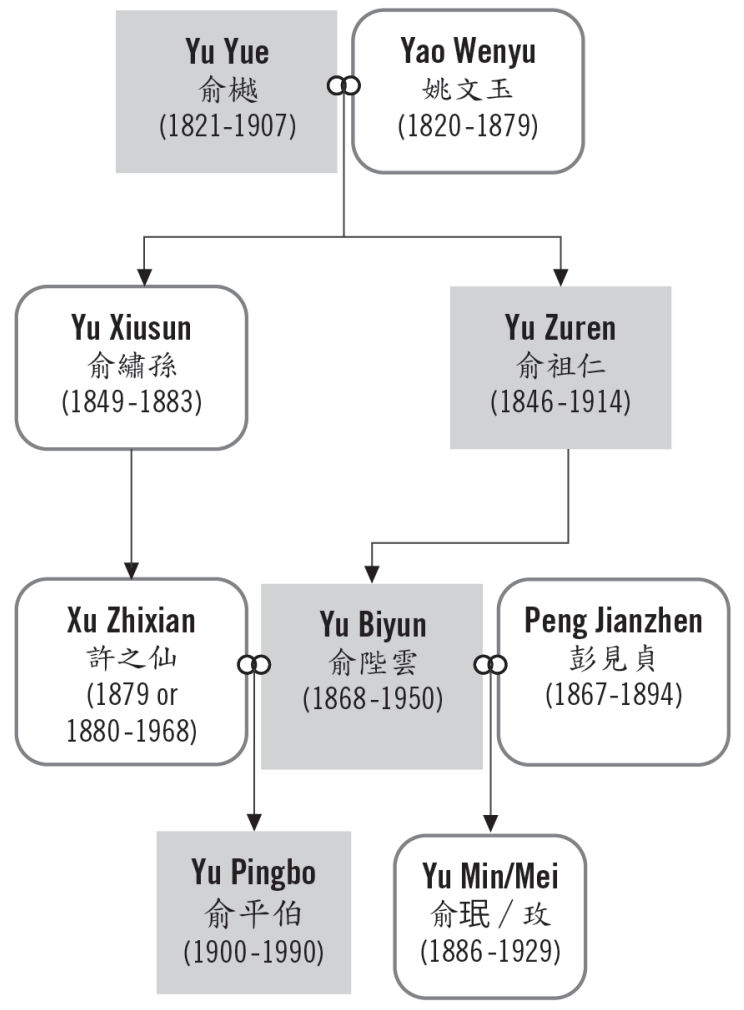

FIGURE I.1. Selected family tree: Introduction. Family trees were produced using the open source software Gramps. Men are in boxes with square corners, women with rounded corners.

\section{Reading the Tree Diagrams}

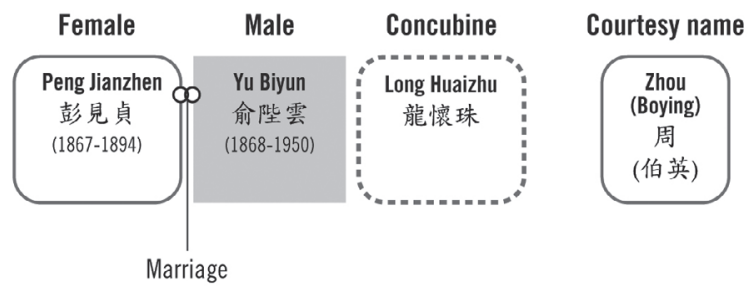

On the tree diagrams, females are indicated by a rounded, outlined rectangle, males are indicated by a gray rectangle, and concubines are indicated with a dashed outline. Marriages are represented by a double-ring icon. Names of people for whom only the courtesy name or a nickname rather than the formal name are known are listed in parentheses. 
of the foremost scholars of the classics in his generation. For a prominent Chinese scholar to have readers in Japan was not surprising; to be actively in correspondence with them was Yu Yue's innovation and a distinctive mark of his late nineteenth-century world. ${ }^{4}$ Written words had been essential to make the tooth grave anything more than a spot of disturbed earth, and for Yu Yue the memory of his commemorative act was completed by this proof of far-ranging publication of private sentiment.

This was not the first unconventional tomb that Yu had built. The year before, after he had buried Yao Wenyu in the hills near Hangzhou and built himself a small rustic retreat beside her grave, he also fulfilled a long-held ambition of constructing a tomb nearby for the manuscripts of the many books he had published in his lifetime (see figure I.2). ${ }^{5}$ The book tomb was an occasion for extended poetic exchange with his friends and students. ${ }^{6}$ As Yu Yue made arrangements for remembering and being remembered during a period he mistakenly assumed was close to the end of his life, his manuscripts took their place near the family grave like human kin. Among the words buried there are memorials to his wife and to other people already buried in other graves.

Yu Yue evidently saw no contradiction, but instead a resonance, between his roles as sentimental widower and prolific senior scholar. The parallels between the two graves suggest that mourning was where his public and familial obligations overlapped. The tooth grave, the book grave, and the words that marked them in one place and spread their legends to many places raise questions: How should we remember the beloved dead? What comfort and meaning should the living find in the traces they leave behind? What purpose can writing, left behind by the dead or composed by the bereaved, serve, either for immediate survivors or for later readers? How are the mourner's attempts to preserve the memory of the departed reconciled with making a chronicle of the self as mourner? How is personal and familial memory shaped by inherited genres and terms on the one hand and cultural transformations on the other? How does a family, bound by shared history, affection, and duty but divided by differences of generation, gender, status, and personality, join their voices in producing the memories of their dead?

These are perennial questions for a species both mortal and literate, for which I offer answers particular to a cultural moment and a family. From the last decades of the nineteenth century through the first decades of the twentieth century, the Yu family and their kin by marriage produced an incomparable series of documents of memory and loss. Their memory writing is compelling because of its quantity, its variety, and the resonance of themes across generations, but also because of its meticulousness in noting what they failed to preserve.

This book covers from the 1870s into the first half of the twentieth century, paying the most intense attention to the years from 1875 to 1897 . Thus 


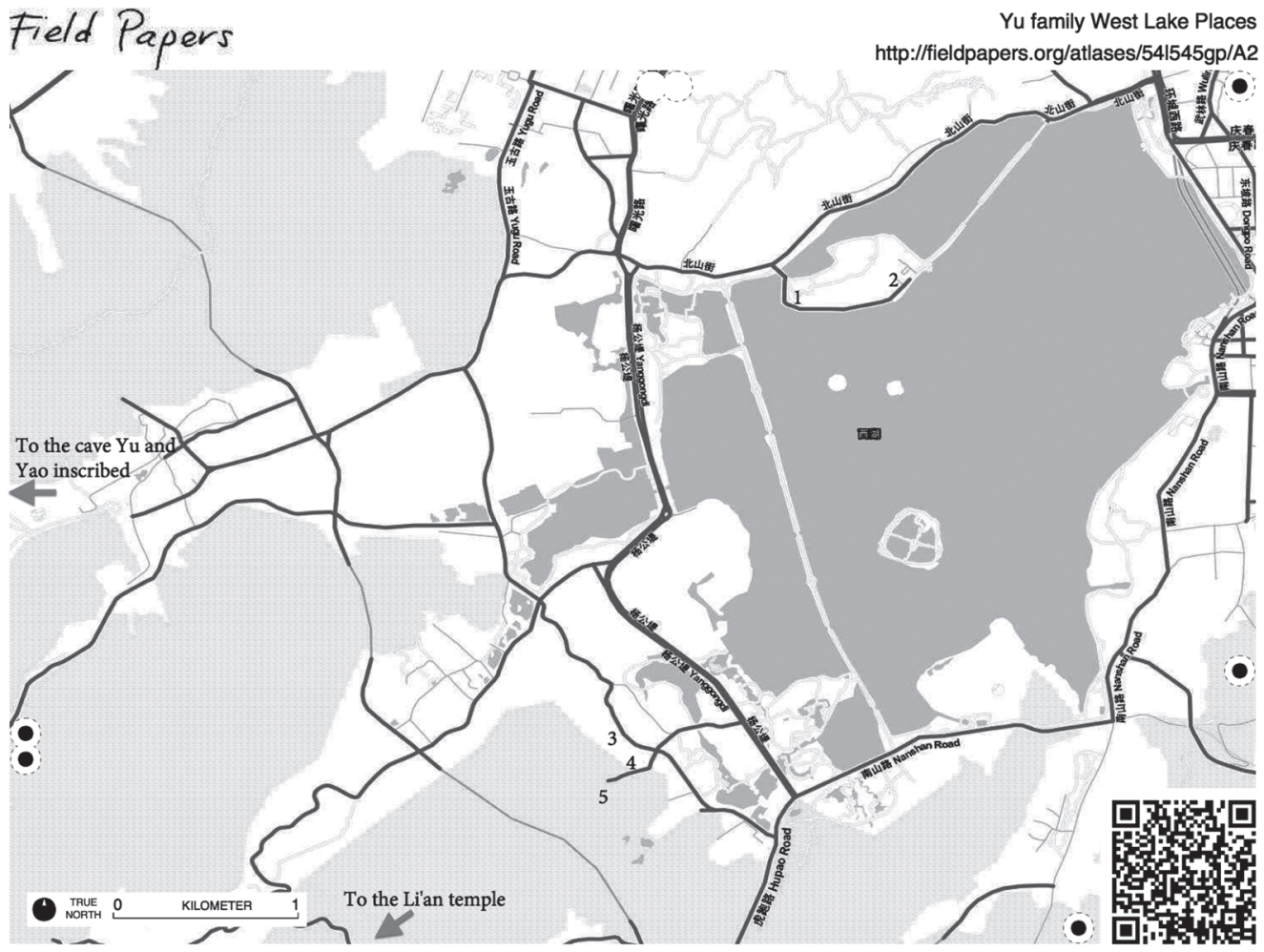

FIGURE I.2 Map of significant places in family history: West Lake

The base map is Open Street Map data using the Field Papers tool. Locations are approximate, based on modern locations of those structures still surviving and late Qing descriptions, as well as the 1929 Hangzhou xihu youlan zhinan.

\section{Yu Lou}

Yu Yue's residence in Hangzhou, built for him by his students and Peng Yulin. The tooth grave is nearby. Its garden is named the "small Quyuan" even though it is physically larger than the original Quyuan in Suzhou. (introduction, chapter 1)

2. The Gujing Jingshe

One of the more prominent Confucian academies, where Yu Yue taught for thirty years.

3. Yao WenYu's grave, with the Youtai xianguan and the book grave nearby. Yu Yue, Yu Shaolai, Yu Zuren, their spouses, and Peng Jianzhen are all buried here. (introduction, chapters 1-3)

4. Chen Kuilong's grave

Chen Changwen and her younger sisters are the first ones buried here. (chapter 5)

5. Yu Xiusun's grave (chapter 2) 
the story of the Yus and their beloved dead plays out across the final decades of the Qing dynasty and the first decades of the Republic of China. When $\mathrm{Yu}$ Yue and Yao Wenyu were in their thirties, their home provinces were ravaged by the violent cataclysm of the Taiping civil war. Although the immediate family survived relatively unscathed, their personal memorial work and $\mathrm{Yu}$ Yue's scholarly career are completed in the context of a wider regional and national project of reconstruction and memorial after unfathomable loss. ${ }^{7}$ Even as they wrote, the technologies of printing and the institutions of publication and book distribution were being transformed. By the time of their greatgrandchildren, the language of education and governance, definitions of scholarship and literature, and map of literary genres had all been remade. The Yu's memory writing reveals the changing tools the family and their peers had to try to convey their loss.

Both Yu Yue and his great-grandson Yu Pingbo (1900-1990) were among the most prominent scholars of their generations. In Qingdai xueshu gailun (An introductory discussion of Qing dynasty scholarship), Liang Qichao (18731929) named Yu Yue as one of the great masters of an age of overall decline. ${ }^{8}$ He was professionally and socially connected to the most powerful men of his day: Zeng Guofan (1811-1872), the general who subdued the Taipings, had been his examiner; Li Hongzhang (1823-1901), viceroy successively of Huguang, Zhili, and Liangguang, was a fellow protégé of Zeng's and recommended him for one of his first positions at a Confucian academy. ${ }^{9}$ Yu's biography in the Qingshi gao includes long lists of two legacies, his prominent students and the books he wrote. ${ }^{10} \mathrm{He}$ led the prestigious Hangzhou academy Gujing jingshe for more than thirty years. ${ }^{11}$ His philological research was distinguished by exhaustive and careful consideration of a wide range of sources, as well as a willingness to differ with accepted interpretations, or even his own previous ideas. He was an advocate of traditional scholarship owing his fame to the radically new structures of publication in his era. The core of his scholarly pursuits focused on bringing the fruits of eclectic reading to bear on canonical texts, but as his fame grew he also published his own eclectic works.

In his final years, Yu Yue personally took charge of his lone, long-awaited great-grandson Yu Pingbo's early education. ${ }^{12}$ After two generations of Yus less prominent for personal and historical reasons, Yu Pingbo successfully mastered the transition between the old and new regimes of education. He attended Beijing University and later became a professor there and at Qinghua. A member of the May 4 generation of scholars and reformers, he was one of the influential scholars of traditional literature when that category was being redefined. Although also an author of new-style poetry and some short fiction, he is most famous as one of the founding scholars of the New Red Studies, attempting to reveal Cao Xueqin's original intentions in Honglou meng and making distinctions between the first eighty and last forty chapters. In 1954, his fame 
turned to notoriety when Mao Zedong singled out his work for criticism as representing a bourgeois and reactionary approach to literature and cultural heritage. A storm of critical articles and meetings followed Mao's lead. ${ }^{13}$ During the Cultural Revolution, he and his wife were sent down to rural Henan, but after rehabilitation in the 1970s he resumed his status as a respected scholar. Alongside his scholarly work, he took on the responsibility of the family's tradition of memory writing.

Surrounding, supporting, and supported by the two famous men are generations of interrelated clans of the aspiring scholar-official class and educated professional class rooted primarily in the Hangzhou and Suzhou areas. The prominence of great-grandfather and great-grandson allowed them privileges to preserve their family's memory unavailable to most; a by-product of two men's fame was the recording of many other voices.

In recent decades, the family and its most famous members have been chronicled by both descendants and unrelated scholars. In the 1990s, Yu Pingbo's son Yu Runmin and his wife wrote Deqing Yushi: Yu Yue, Yu Biyun, Yu Pingbo. ${ }^{14}$ Xie Chaofan wrote a wide-ranging and detailed study of Yu Yue's work in various genres. ${ }^{15} \mathrm{Xu}$ Yanping discussed the case of Yu Yue and Yu Pingbo in a book about traditions of family education and literature in the Qing. ${ }^{16}$ Wang Yanying meticulously edited, dated, and annotated a large collection of Yu Yue's letters, including many never previously published. ${ }^{17}$ Attention to the Yus is furthermore of renewed interest among multigenerational literati families of the late Qing and Republican era, both general readers and scholars in China as well as scholars outside of China. Susan Mann takes a similar generational approach to another nineteenth-century family in The Talented Women of the Zhang Family. ${ }^{18}$ Joseph W. Esherick traces a family's history through the nineteenth and twentieth centuries in Ancestral Leaves: A Family Journey through Chinese History. ${ }^{19}$ A special issue of the journal Nannü: Men and Women in Late Imperial China dedicated to late Ming and early Qing men's mourning writing for beloved women discusses precedents the Yus were often keenly aware of. ${ }^{20}$

My purpose here is not to duplicate efforts of others writing about the Yus by producing a comprehensive family history; in particular, the scholarly and administrative careers of male family members, precisely the parts of their lives they assumed to be the most important to posterity, are largely beyond my scope. This is a partial account, focusing on the questions of how memory was crafted, preserved, and transmitted as much as on what was remembered.

\section{SETTING THE TERMS}

In their writings, the Yu family have given me sets of terms and images to address the questions of memory and writing I just raised. First are three verbs of memory and its preservation: $y i$ 憶 (to remember), $j i$ 記 (to remember or to 
record), and chuan 傳 (to transmit). Second are three sets of images, varying in the degree to which they are culturally shared or specific to the family's history: $q u$ 曲 (curved, partial, yielding) and quan 全 (complete); falling or fallen flowers luo hua 落花 and the grasses fortunate enough to survive a fire xingcao 幸草; and finally ink, tears, and the moisture left by touch.

In the autumn of 1894, Yu Yue's grandson and Yu Pingbo's father Yu Biyun (1868-1950) published two poetry collections mourning his wife, Xuanhuashi shiji (Poetic records from the chamber of patterned splendor) and Xuanhuashi shiyi (Poetic recollections from the chamber of patterned splendor), whose titles differ only by a single character. The first is a record of the surviving samples of his late wife's handwriting, the second a chronicle of his experiences and recollections during the days between her death and burial. $J i$ 記 and $y i$ 憶 together make up the modern Chinese compound for memory, but $\mathrm{Yu}$ Biyun's use suggests the difference between them. On the level of the radicals with which the words are written, $j i$ is an action of words, and $y i$ of the heart and mind. Ji can be both to remember and make a record for the purposes of memory; it can be to memorize, as well as personal memory. $Y i$ lacks the dimension of writing or recording, and focuses exclusively on personal memory rather than the recall of information. ${ }^{21}$

For either memory in the mind or memory written down to outlast the individual or the single copy, the essential act is chuan, to transmit. It was an obligation for men of the literati class to transmit accounts of all worthy people incapable or less capable of leaving their own records: the dead, the illiterate, women both literate and not, and literate men who were unsuccessful in their political and literary careers. The family did not know to speak of "the work of grief," but ritual and textual obligations to the dead weighed heavily on the men of their class. It was Yu Yue's great ambition to be a chuanren 傳人, a transmitter of the great knowledge of the past. ${ }^{22} \mathrm{He}$ earned that status with commentaries on the classics that take pride of place in the first volumes of his collected works, but the prestige he gained thereby allowed him to transmit accounts of individuals, in his own and other families.

One name he succeeded in transmitting is that of the garden he and Yao Wenyu built on the small arc of land left over after construction their new home in yihai (1875). The plot's shape inspired the garden's name, Quyuan, an allusion to the Daode jing (see chapter 1). Qu ze quan 曲則全 is the first of a series of terms giving rise to their opposites, the flawed or incomplete becoming the perfect and complete. Legge translates it as "The partial becomes complete," D. C. Lau as "bowed down then preserved," and Richard John Lynn as "Stepping aside, but keeping one's wholeness intact." ${ }^{3}$ Over the following decades, the Quyuan was not only a physical setting for solitary writing and family gatherings, often involving exchange of poems, but also a virtual textual space, given that Yu Yue and others in the family named books for the garden and the buildings within it. Yu Yue himself became most well known under the 
name Yu Quyuan. Chinese garden design strives to represent a world in microcosm. In both the garden itself and the textual enclosures it inspired, through repeated losses and transformations, the Yu family and their kin attempt to construct a complete world in the small space left to them. $Q u$ and quan are not specifically terms for memory, but creating a whole out of a fragment is one of its essential acts. ${ }^{24}$

The plants in a garden provide humans with markers for the losses and recurrences of seasonal time. At the dawn of his career, Yu Yue wrote his most famous poetic line. Given the examination topic of falling or fallen flowers, he wrote, “The flowers fall but the spring remains” 花落春仍在, and is praised for this refusal to lapse into conventional melancholy by one of the most powerful and influential men of his day, Zeng Guofan. Through the subsequent decades, although Yu feared that his aborted political career had failed his mentor, he hoped that his writing could be the spring that outlasts the fragile flowers ${ }^{25}$ (see chapter 1). By making Chunzai (The spring remains) the name of both the formal hall in his residence and the title for his collected works, he repeatedly inscribes his assertion of continuity.

Four generations later, the poetic couplet by his great-granddaughter $\mathrm{Yu}$ Min (1886-1929) that lingered in her kin's memories after she died is a particularly heartrending treatment of falling leaves 永夜青燈仍策策, 故人黃土 已年年. “Throughout the endless night by the lonely lamp they still rustle $c e-c e$, my old friend in the grave soil already year upon year" 26 (see chapter 5). Although her father and younger brother remembered her couplet, quoting it in their writings that mourned her, the poem containing the lines had been lost. Falling flowers and leaves, marks of change in the transitional seasons spring and autumn, had been conventional poetic topics for centuries when both the great-grandfather and the great-granddaughter wrote. Mortals describing this ephemeral and recurrent detritus of the cycles of life, in poems that may outlive their authors, consciously sound the resonances between continuity and loss. The contrast between the plentitude of copies of the man's words and the almost total absence of the woman's repeats many times in the family's history.

More violent calamities threaten the survival of words. Before her death, $\mathrm{Yu}$ Yue's daughter Yu Xiusun burned her own collected poems. Her father reassembled what he could from boxes of correspondence and other people's recollection, publishing the collection under the title Huifulou xingcao (Provident grasses of the hall of brilliance and good fortune), in reference to a passage in a Han-era text about grasses that survive a conflagration. ${ }^{27}$ Four generations later, Yu Pingbo referred to this title twice: the first time when making copies of his three sisters' poetry in the 1970s, the second when restoring his own a decade later. ${ }^{28}$ After his handwritten manuscripts were burned during the Cultural Revolution, he assumed that his poetry collection was irretrievably lost. When, in the 1980s, another scholar presented him with a collection painstakingly 
reassembled from pieces published in newspapers, he was inspired to complete the work of reconstruction himself, using "Provident Grasses" in the title in reference to his great-aunt's work. ${ }^{29}$

Through the decades between the lingering spring and the last provident grasses, three fluids are in circulation in the Yus' mourning works: ink, tears, and shouze, perspiration from the hands of the deceased that still clings to objects they had touched. The locus classicus for shouze is in the Li ji (Book of rites): "After one's father dies, one cannot read one's father's books, because the sweat of his hands remains there; after one's mother dies, one cannot drink of the bowls and cups, because the moisture of her lips remains there” 父殆而不能讀 父之書, 手澤存焉爾; 母殆而杯圈不能飲焉, 口澤之氣存焉爾.30 “Father's books" is ambiguous, and soon the term is used to refer to the written work the deceased have left behind as well as the books they owned. Each of these fluids soon dries, but ink is the least ephemeral because the traces it leaves are decipherable. Thus ink must make note of tears and the traces of touch. The relationship between the three is cyclical: awareness of the presence of the touch of the deceased on works written in ink produces tears, and those tears are documented in new works written in ink.

\section{CHAMBERS, GARDENS, AND GENRES}

The family's memories are shaped and organized by several systems: a physical and textual geography, different genres of writing, kinship ties, and calendars of mourning.

In his formidable textual production, Yu Yue constructed virtual spaces named after the physical sites of his life. The physical does not necessarily proceed or determine the virtual; a man can maintain a "study name" even as the places where he writes change. Yu Yue began titling books with the name of the Chunzaitang (Hall where spring remains) before the Chunzaitang in Suzhou existed. Beginning in wuchen (1868), he split his time between his home in Suzhou and teaching by West Lake in Hangzhou; in wuyin (1878), his disciples and his friends built him a residence there, the Yulou. After Yao Wenyu died, he chose a gravesite for her in the nearby hills and built a simple dwelling, the Youtai xianguan (Transcendent's abode at Mount Youtai), next to it. From this point, he divided both his physical and his textual life across these three spaces: the familial garden, the lakeside assembly of students, and the widower's retreat in the hills. The tooth grave is near the Yulou, the book grave by the Youtai xianguan. Each place has at least one book named for it, and the tiny Quyuan also contained several distinct named spaces. The younger generations of the family accompanied him to all three places. Many of them, both male and female, create or have created for them literary spaces named for rooms and other structures within the family's residence, often by Yu Yue; the grandson Yu Biyun, for example, named his poetry collection after the Xiao zhuliguan 
(Small lodge in the bamboo), although the collection was published decades after he had left the building bearing that name.

Names given to literate women's dwelling places, and thus to their writings, follow them from their natal to their marital families. Unlike the men's, these virtual literary spaces often become known outside the family only after their deaths. If the woman left no works to sustain a virtual literary space, a man might write in her stead. When Yao Wenyu left no work for Yu Yue to publish, he himself recreated and reinhabited her Chaxiangshi (Tea fragrance chamber); Yu Biyun in turn created the two works named for his late wife Peng Jianzhen's Xuanhuashi (Chamber of patterned splendor).

To recall their beloved dead and construct their virtual chambers and gardens, the Yus wrote every genre at their disposal: funerary biographies, poems and song lyrics, explanatory commentary on poetry, miscellaneous notes (biji), strange tales, prefaces, verse endorsements of other's literary work (tici), letters, inscriptions on books and places, calligraphic copies of other people's words, and diaries. Each genre offers a different way to address the living and the dead, to contain the voices of both, and to describe and transform daily life and time.

\section{KINSHIP TIES AND MOURNING CALENDARS}

For the living, kinship ties shape not only the kinds of daily intimacies and attention shared, but also the way that these are rendered in the written record. Transformed but not erased, these same ties dictate the obligations and liberties of commemoration after death. The tie of husband and wife is the most well represented in this book, but alongside it are the bonds of parent and child, father-in-law and daughter-in-law (or granddaughter-in-law), adult child and parent, brother and sister, cousin and cousin, friend and friend.

Funeral ritual and mourning mark the transformed status of both the dead and the kin left behind. For the dead, stages advance their separation from the living, from being enclosed in the coffin to burial in the grave. For the living laboring to complete these tasks for the dead, the special clothing and behavioral restrictions of mourning mark their transitional status. But the duration of the changes marks the ultimate separation: the dead should remain encoffined and buried, but the living must at an appointed time take off their mourning garb and reassume the clothes and acts of ordinary life. The severity and length of mourning were one of the chief ways kinship was defined in a complex ranking of relationships across the generations and households. ${ }^{31}$

Funerary rituals were complicated and prolonged. The period between death and burial could be quite long, and the gravesite geographically distant from the place the deceased had lived. Even when the family had the economic means to bury their dead, the length of time between death and burial for welldocumented family deaths between 1879 and 1894 ranged from four months (for Peng Jianzhen) to eleven months (for Yu Xiusun). If a "proper" burial had 
not been possible at the time, a reburial could happen decades later; Yu Yue reburied his father twenty-one years after his death.

After the dead are safely settled in the grave, dates are set aside for remembrance: for specific individuals, the anniversaries of their death and their birthdays; and for the collective dead, the Qingming festival in the spring, tending the ancestral tombs; the Zhongyuan festival in the autumn, praying for the salvation of lost souls; and offerings to the ancestors marking the beginning of each new year. Similarly there were two official sites of remembrance, the grave and the spirit tablet in the household ancestral shrine. Individual anniversaries rather than collective offerings, and the grave instead of the tablet, are more likely to prompt writing.

Mourning writing both is shaped by these temporal, physical, and ritual structures and exceeds them. Certain genres, like the tomb inscription, are obligatory parts of the process of separation of the living from the dead. Much of the family's mourning writing is done in the liminal period between death and burial, so that the process of writing parallels the ritual process of settling the dead in their new place in the grave, the mourner clothed in the reminders of loss. Yet in this book are also many documents of grief disproportionate to the official degree of kinship and outlasting the prescribed mourning period. Memory came unbidden at times other than the regular anniversaries, and some of the bereaved construct additional memorial spaces beyond the grave or the spirit tablet.

\section{ELEGIAC INHERITANCE}

We can place the Yu family's work within two genealogies of mourning writing, one in which they place themselves with their allusions and one into which later readers place them. The Yus themselves are most explicitly mindful of poets from the dynasties before them: Pan Yue (247-300), the first famous writer of poetry mourning a wife, who introduced the theme of dwelling over traces of his late wife's writing; the Tang poet Yuan Zhen (779-831); the Song prose writer Zeng Gong (1018-1093); and the Song poet Zhou Zizhi (10821155). The Yus expanded on phrases from these writers, or used them as shorthand to communicate the situation of mourning.

Martin Huang argues for a trend of "secularization of memory," ordinary and trivial personal memory of the deceased replacing idealized depictions, from the early sixteenth century. ${ }^{32}$ Nonetheless, most of the literature of mourning remains important primarily to the families that produced it. The remembrances that have won a wide readership outside the family or scholarly circles, particularly modern readers, are those in which emotion overcomes duty. Mao Xiang's (1611-1693) Yingmeian yiyu (Words of remembrance from the shadowed plum retreat), remembering his concubine Dong Xiaowan, was already famous and imitated in Yu Yue's time. Although Yu Yue was aware of 
Ye Shaoyuan's (1589-1648) familial anthology Wumeng tangji (Collection of the hall of noon dreams), probably the most celebrated document of mourning both a wife and daughters, he never explicitly modeled himself on it. Most famous now and first published during Yu Yue's lifetime is Shen Fu's (1763-?) Fusheng liuji (Six records of a life adrift). ${ }^{33}$ Mao and Shen's books are informal prose works in whole or in part exclusively devoted to memory of the lost beloved woman, one of few forms that the Yus did not compose.

Writing when the trend toward inclusion of worldly detail in mourning pieces had been continuing for centuries, Yu Yue would not have described himself as an innovator. It is in the multiplicity of genres in which he undertook his task and the volume of work he was able to transmit that he and his family represent a culmination of the tradition. Nevertheless, his descendants, particularly Yu Biyun and Yu Pingbo, made some innovations when faced with their daunting and expansive family legacy.

\section{CHAPTER OUTLINE}

These chapters are chronological, following the generations of the family, but the works referred to violate chronology, because later generations often look back and recall earlier ones. The prologue concerns Yu Yue's parents. Chapter 1 discusses Yu Yue's writings devoted to his wife, Yao Wenyu. Chapter 2 deals with memories of their children, particularly the starkly contrasting cases of their second son Yu Zuren and youngest daughter Yu Xiusun. Chapter 3 centers on a single work that Yu Yue's grandson Yu Biyun devoted to his wife, Peng Jianzhen. Chapter 4 discusses Yu Yue's granddaughter Yu Qingzeng and, to a lesser extent, his maternal granddaughter $\mathrm{Xu}$ Zhiwen. The final chapter deals with memories of the great-grandchildren's generation, Yu Biyun and Peng Jianzhen's two daughters Jin and Min (Mei), as well as a cousin, Chen Changwen, and Jin and Min's much more famous half-brother Yu Pingbo.

The irony that I know more about the Yu family in the second half of the nineteenth century than my own natal or marital ancestors in the same period, even those well documented in the written record, is not lost on me. Yu Yue and his entire family would surely find this both wrongheaded and bizarre, Confucius having written that "To offer sacrifice to the spirit of an ancestor not one's own is obsequious." ${ }^{4}$ But I am convinced when they collected the traces of the beloved dead and explicated them so precisely Yu Yue, Yu Biyun and the others' hopes were not limited to the most likely readers.

\section{NOTES ON TRANSLATION}

Most of the people involved in this story had at least two names, a personal name ming and a polite name zi; some also had additional childhood names, nicknames, pen names, and posthumous titles. When translating texts, I use 
the name that the writer used, clarifying the reference in parenthetical notes when appropriate. When writing in my own voice, I follow contemporary conventions and refer to members of the family by their personal names or surname and personal name. Many married women, including Yu Yue's mother and both of his daughters-in-law, are recorded in the written record with only their surname followed by shi (meaning née). I refer to them by their surname alone except when the identification could refer to more than one woman.

Most of the texts use dates on the traditional lunar calendar, identifying the year by its designation on the sixty-year cycle of heavenly stems and earthly branches, or sometimes by the year of an emperor's reign. Although most of the year gengyin in the Guangxu reign, for example, overlaps with most of 1890 , it is not identical, beginning on January 21 and ending on February 8, 1891. The every ten-year repetition of the heavenly stem and every twelve-year repetition of the earthly branch shaped the family's sense of time. To maintain that sense, I therefore keep these terms in pinyin, adding a Gregorian calendar equivalent in parentheses. Each season lasts three lunar months. I translate the lunar months as "the first month," "the second month," and so on. Adding approximately one month provides an estimate for the Gregorian equivalent.

Traditional ways of counting age consider people at least one year older than the Western system (one is "one sui" during the year of one's birth, and at lunar new year the following year one is considered "two sui"); in translations, I give the numbers as written in the original texts, putting the Western count in parentheses; when writing in my own voice, I use the Western system. 
